\title{
Sevuparin binds to multiple adhesive ligands and reduces sickle red blood cell-induced vaso-occlusion
}

\author{
Marilyn J. Telen, ${ }^{1}$ Milena Batchvarova, ${ }^{1}$ \\ Siqing Shan, ${ }^{1}$ Petra H. Bovee-Geurts, ${ }^{2}$ \\ Rahima Zennadi, ${ }^{1}$ Anna Leitgeb, ${ }^{3}$ \\ Roland Brock ${ }^{2}$ and Maria Lindgren ${ }^{3}$ \\ ${ }^{1}$ Division of Hematology, Department of Medi- \\ cine, Duke Comprehensive Sickle Cell Center, \\ Duke University School of Medicine, Durham, \\ NC, USA, ${ }^{2}$ Department of Biochemistry, \\ Radboud University Medical Center, Nijmegen, \\ The Netherlands and ${ }^{3}$ Dilaforette AB, Stockholm, \\ Sweden
}

Received 31 March 2016; accepted for publication 27 June 2016

Correspondence: Marilyn J. Telen, Box 2615 DUMC, Duke University Medical Center, Durham, NC 27710, USA.

E-mail: marilyn.telen@duke.edu

\begin{abstract}
Summary
Sevuparin is a novel drug candidate in phase II development as a treatment for vaso-occlusive crises (VOC) in patients with sickle cell disease (SCD). As a heparin-derived polysaccharide, sevuparin has been designed to retain antiadhesive properties, while the antithrombin-binding domains have been eliminated, substantially diminishing its anticoagulant activity. Here, we demonstrate that sevuparin inhibits the adhesion of human sickle red blood cells (SS-RBCs) to stimulated cultured endothelial cells in vitro. Importantly, sevuparin prevents vaso-occlusion and normalizes blood flow in an in vivo mouse model of SCD vaso-occlusion. Analyses by surface plasmon resonance (SPR) and fluorescence correlation spectroscopy (FCS) demonstrate that sevuparin binds to $\mathrm{P}$ - and L-selectins, thrombospondin, fibronectin and von Willebrand factor, all of which are thought to contribute to vaso-occlusion in SCD. Despite low anticoagulation activity, sevuparin has anti-adhesive efficacy similar to the low molecular weight heparin tinzaparin both in vitro and in vivo. These results suggest that the anti-adhesive properties rather than the anticoagulant effects of heparinoids are critical for the treatment of vaso-occlusion in SCD. Therefore, sevuparin is now being evaluated in SCD patients hospitalized for treatment of VOC.
\end{abstract}

Keywords: sickle cell disease, cell adhesion, adhesion receptors, vasoocclusion, heparinoids.
Sickle cell disease (SCD) is the most common haemoglobinopathy, affecting millions of people worldwide (Weatherall, 2010). A single point mutation in the sixth codon of the $\beta$-globin gene $(H B B)$ results in the synthesis of abnormal sickle haemoglobin (HbS), which polymerizes and causes red blood cell (RBC) deformation ('sickling') under hypoxic conditions. RBCs containing predominantly HbS (SS-RBCs) also demonstrate an adhesive phenotype, (Hebbel et al, 1980a) and the degree of adhesiveness is correlated with vaso-occlusive crisis (VOC) frequency (Hebbel et al, 1980b). Vaso-occlusion, the pathognomonic finding of SCD, involves binding of blood cells to the endothelium. SS-RBCs adhere to and activate endothelial cells and leucocytes, and also stimulate coagulation (Kaul \& Hebbel,2000; Brown et al, 2001; Zennadi et al, 2007, 2008; Ataga et al, 2012). Hypoxia/reperfusion injury also results in leucocyte activation, chronic and acute inflammation, and endothelial activation and damage (Frenette, 2002). All of these events, particularly the adhesiveness of both leucocytes and SS-RBCs to endothelial receptors, contribute to VOC (Manwani \& Frenette, 2013), the most common clinical consequence of SCD with the exception of chronic haemolytic anaemia.

Pain is a hallmark of SCD (de Montalembert, 2008; Steinberg, 2011; Ballas \& Darbari, 2013), can be acute or chronic, and is most often located in the back, chest, joints and the long bones of the extremities. VOC presents as acute pain that can last for several days to a week or more (de Montalembert, 2008; Steinberg, 2011). The frequency and severity of such painful episodes vary among patients (de Montalembert, 2008; Steinberg, 2011).

The initial attachment of SS-RBCs to the vessel wall has previously been demonstrated to be mediated by very shortlived interactions via selectins (Matsui et al, 2001, 2002; Burnette et al, 2011; Gutsaeva et al, 2011; Kutlar et al, 2012). Following further cascade activation, firm attachment of SSRBCs and leucocytes occurs mainly via interactions with integrins, causing subsequent vessel obstruction (Kaul et al, 2000, 2006; Zennadi et al, 2004, 2007, 2008; Finnegan et al, 2007a). P-selectin contributes to SS-RBC adhesion and vasoocclusion both in vitro and in vivo (Matsui et al, 2001, 2002; 


\section{J. Telen et al}

Embury et al, 2004; Burnette et al, 2011). P-selectin blockade can improve blood flow and can decrease serum markers of disease in patients with SCD (Kutlar et al, 2012). In addition, E-selectin is upregulated during inflammatory processes (Ebnet \& Vestweber, 1999; Parent \& Eichacker, 1999; Langer \& Chavakis, 2009) and participates in white blood cell adhesion in SCD (Turhan et al, 2002; Zennadi et al, 2008). However, as E-selectin is also an important immune component in response to infections, blocking E-selectin could theoretically be detrimental in infection-induced VOC. L-selectin contributes to lymphocyte and neutrophil trafficking and is cleaved from leucocytes during activation. Children with SCD and a history of silent cerebral infarct (SCI) have significantly higher soluble L-selectin levels than non-SCI patients, (Faulcon et al, 2013) suggesting that increased inflammatory responses may be associated with disease severity (Kinney et al, 1999; Faulcon et al, 2013). Although not yet demonstrated, blockade of adhesive interactions via L-selectin could be beneficial in SCD, especially in this group.

While cell-cell interactions between SS-RBCs and the endothelium are necessary for VOC to occur, VOC pathogenesis also involves endothelial cell activation and changes in the levels of various plasma proteins (Pathare et al, 2003; Finnegan et al, 2007b; Sparkenbaugh \& Pawlinski, 2013). Several nonmembrane bound proteins, such as von Willebrand factor (VWF) (Krishnan et al, 2008; Zhou et al, 2009; Chen et al, 2011) and thrombospondin (TSP) (Brittain et al, 1993, 2001a, b; Novelli et al, 2012), may contribute by serving as anchoring or bridging proteins, and several of these proteins have heparin-binding sites. Furthermore, both heparin and low molecular weight heparins (LMWHs) can bind to several adhesion proteins (Koenig et al, 1998; Gupta et al, 1999; PolanowskaGrabowska et al, 2010; Burnette et al, 2011) to inhibit SS-RBC adhesion (Barabino et al, 1999; Matsui et al, 2001, 2002; Gayen Betal \& Setty, 2008) and to restore blood flow in animal models of SCD (Embury et al, 2004).

In a clinical study of patients with SCD who were experiencing acute VOC, treatment with anti-thrombotic doses of the LMWH, tinzaparin, resulted in significant reductions in VOC duration, the number of days with severe pain and hospitalization duration (Qari et al, 2007). However, bleeding events required treatment cessation in some patients (Qari et al, 2007). Thus, while heparins and LMWHs have anti-adhesive and anti-inflammatory properties, as well as anticoagulant effects, all of which are potentially beneficial in VOC treatment, the associated risk of bleeding has slowed further clinical testing of heparinoids in SCD patients (Lever \& Page, 2002; Qari et al, 2007; Shah et al, 2013).

Sevuparin (DF02) is a novel drug candidate currently in early phase development for VOC treatment in patients with SCD and parsite caused RBC adhesion in malaria (NCT02515838 and NCT01442168, respectively). Sevuparin is a negatively charged polysaccharide derived from heparin through chemical depolymerization, in which the specific pentasaccharide that is involved in high-affinity binding to antithrombin III is deleted. As a result, sevuparin has no direct effect on factor Xa nor on thrombin, and the effect on the activated partial thromboplastin time (aPTT) is markedly reduced in comparison with heparin and LMWH (Lindgren et al, 2015). Here, we demonstrate the binding characteristics of sevuparin with proteins involved in SCD vaso-occlusion and provide evidence of the pronounced anti-adhesive properties of this new potential treatment. Finally, we demonstrate that sevuparin improves blood flow in an in vivo model of VOC, likely through a multi-factorial mechanism of action involving several adhesion proteins.

\section{Materials and methods}

\section{Sevuparin}

Sevuparin, like other members of the chemical class of heparins, is polydisperse, encompassing a range of polysaccharide chain lengths. Sevuparin chains range in molecular weight from 1.2 to $15 \mathrm{kDa}$. The predominant size is $6-16$ disaccharide units of 2-N-sulfo-6-O-sulfo-glucosamine and iduronic-2-O-sulfate acid, which corresponds to molecular weights of $3.6-9.6 \mathrm{kDa}$. The average molecular weight is approximately $8 \mathrm{kDa}$. The predominant chemical structure of sevuparin is illustrated in Fig 1. Sevuparin does not contain the specific binding sequence for antithrombin; as a consequence it has minimal anti-Xa and anti-IIa activity compared to other heparinoids (Table SI in Data S1).

\section{Synthesis of fluorescein-labelled sevuparin}

For direct interaction measurements with target proteins by fluorescence correlation spectroscopy (FCS), fluoresceinlabelled sevuparin was purchased from EMC Microcollections $\mathrm{GmbH}$ (Tübingen, Germany), which performed sevuparin labelling via its free carboxy groups using standard ethylenedi-carbodiimide coupling.

\section{Surface plasmon resonance measurements}

Surface plasmon resonance biosensor technology (SPR, Biacore, GE Healthcare, Diegem, Belgium) was used to compare the interactions of sevuparin, LMWH (tinzaparin) and fulllength heparin. P-, E-, and L-selectin Fc chimeras (R\&D Systems, Minneapolis, MN, USA) were attached via anti-Fc antibodies to the sensor chip, and binding of sevuparin from solution to the immobilized selectins was recorded in real time. The data were subjected to both one-site and two-site binding non-linear analysis in GraphPad Prism (GraphPad Software, Inc., La Jolla, CA, USA).

\section{Fluorescence correlation spectroscopy}

Fluorescence correlation spectroscopy autocorrelation measurements employed the FCS unit of a Leica TCS SP5 
Fig 1. Chemical structure of sevuparin. The diagram represents the predominant chemical structure of sevuparin with the main monosaccharide constituents. Sevuparin is a polysaccharide-based drug that is designed to retain the anti-adhesive properties of heparin. The mean molecular weight of sevuparin is approximately $8 \mathrm{kDa}$.

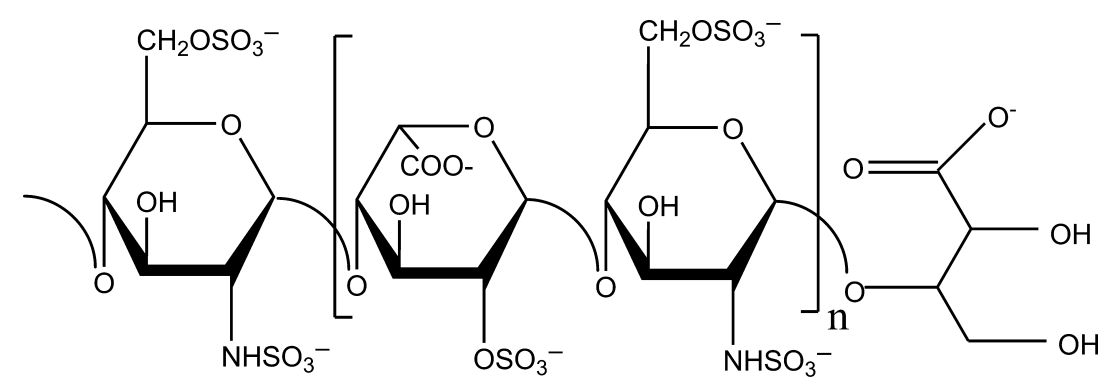

confocal microscope equipped with an HCX PL APO $63 \times$ N.A. 1.2 water immersion lens (Leica Microsystems, Mannheim, Germany). Autocorrelation functions were analysed using ISS VISTA software (http://www.iss.com/microscopy/software/vistavision.html). Fitting was performed according to a 3D-Gaussian diffusion model, assuming two diffusing components and a triplet component. The fractions of bound and free ligand were obtained from the fractional contributions of the slow and fast diffusing components of the autocorrelation functions (Mader et al, 2004). The particle number obtained from the fit was corrected for uncorrelated background (Eq. 1), (Koppel, 1974)

$$
\mathrm{G}_{\text {tot }}(0)=1+1 / \mathrm{N}_{\mathrm{app}}=1+\left(1-\mathrm{CPS}_{\mathrm{b}} / \mathrm{CPS}_{\mathrm{t}}\right)^{2} / \mathrm{N}_{\text {corr }}
$$

where $\mathrm{CPS}_{\mathrm{t}}$ is the total signal (counts per second), $\mathrm{CPS}_{\mathrm{b}}$ is the background signal, $\mathrm{N}_{\text {app }}$ is the apparent particle number obtained from the fit to the autocorrelation function and $\mathrm{N}_{\text {corr }}$ is the corrected particle number. The ratio of total fluorescence divided by the number of particles gives the counts per molecule (CPM), which is the measure of the average brightness of each particle. The CPM as a measure of molecular brightness was then determined according to (Eq. 2).

$$
\mathrm{CPM}=\left(\mathrm{CPS}_{\mathrm{t}}-\mathrm{CPS}_{\mathrm{b}}\right) / \mathrm{N}_{\mathrm{corr}}
$$

\section{$R B C$ collection and preparation}

Blood samples from patients who were homozygous for $\mathrm{Hb} \mathrm{S}$ were collected into citrate tubes according to an Institutional Review Board (IRB)-approved protocol. Blood samples were collected without regard for presence of absence of hydroxycarbamide (also termed hydroxyurea) therapy; donors were excluded if they had experienced vaso-occlusion within the preceding 3 weeks or had been transfused within the last 3 months. RBCs were washed in phosphate-buffered saline (PBS, pH 7.4), and the plasma and buffy coat were removed.

\section{In vitro adhesion assays}

RBC adhesion assays were performed in a graduated height flow chamber as described previously (Zennadi et al, 2004). RBCs were labelled with a PKH-26 red fluorescent cell linker kit (Sigma, St. Louis, MO, USA) following the manufacturer's instructions before adhesion assays. Confluent human umbilical vein endothelial cells (HUVECs) were grown and prepared on glass slides that had been coated with $2 \%$ gelatin (Sigma). P-selectin expression was induced by treating HUVECs with $50 \mathrm{ng} / \mathrm{ml}$ interleukin (IL) 13 (R\&D Systems) for $48 \mathrm{~h}$ in culture medium without heparin (EGM-2, Clonetics, Walkersville, MD, USA) at $37^{\circ} \mathrm{C}$ and $5 \%$ $\mathrm{CO}_{2}$, washing with PBS++ (PBS with $\mathrm{Ca}^{2+}$ and $\mathrm{Mg}^{2+}$ ) and stimulating with histamine $(100 \mu \mathrm{mol} / \mathrm{l}$, Sigma $)$ in PBS++ for $10 \mathrm{~min}$ at $37^{\circ} \mathrm{C}$ (see Data $\mathrm{S} 1$ ). For inhibition experiments, slides were incubated for $20 \mathrm{~min}$ at $37^{\circ} \mathrm{C}$ with sevuparin, antibodies or tinzaparin, washed again, and then mounted in the flow chamber. An RBC suspension (0.05\%) was infused at a constant flow rate, determined by the heights measured in the adjustable flow chamber, to achieve the desired range of shear stresses $\left(0 \cdot 3-5\right.$ dynes $\left./ \mathrm{cm}^{2}\right)$. After RBCs had been infused through the chamber for $2 \mathrm{~min}$, adhesion events were counted for $2 \mathrm{~min}$ at each of seven different locations along the length of the slide during continuous flow. Events counted included both transient and permanent adhesion, and each field counted was $0.25 \mathrm{~mm}^{2}$ in area. The number of adhesion events was then calculated as cells $/ \mathrm{mm}^{2}$ at various shear stresses, and the shear stress at each point inside the flow chamber was calculated as previously described (Zennadi et al, 2004).

\section{Mouse model of human sickle RBC adhesion and vaso- occlusion}

Adhesive events and vaso-occlusion were studied in an adoptive nude mouse (Jackson Laboratories, Bar Harbor, ME, USA) model. In this model, infused human SS-RBCs cause vaso-occlusion, which is directly observed in subcutaneous vessels through implanted window chambers, as previously described in detail (Zennadi et al, 2007, 2012; Zennadi, 2014). This model has the advantage of using human SSRBCs. Murine SS-RBCs lack several human RBC adhesion molecules, including the laminin receptor basal cell adhesion molecule/Lutheran antigen (BCAM/Lu, CD239) and the multifunctional receptor involved in RBC-leucocyte adhesion, CD44. The role of activation of red cell adhesion receptors may also be different (Trinh-Trang-Tan et al, 2010). In our adoptive model, a minority population of human SS-RBCs causes vaso-occlusion comparable to vaso-occlusion occurring in transfused SCD patients; moreover, we have shown 


\section{J. Telen et al}

that these events also include adhesion of (murine) leucocytes, as they are believed to do in human illness (Zennadi et al, 2008). Finally, studies of inhibitors of signalling pathways important in vaso-occlusion suggest that findings using this adoptive model are well-replicated using sickle cell mouse models (Zennadi, 2014; Zhao et al, 2016).

Dil (Molecular Probes, Thermo Fisher Scientific, Waltham, MA USA) dye was used to label SS-RBCs. A window chamber consisting of a double-sided titanium frame was surgically implanted into the dorsal skinfold of each mouse, and animals were allowed to recover for 3-5 days to allow healing. To upregulate endothelial selectin expression and to promote SSRBC adhesion and vaso-occlusion, $500 \mathrm{ng}$ murine tumour necrosis factor $\alpha$ (TNF $\alpha$; Peprotech, Rocky Hill, NJ, USA) in $100 \mu \mathrm{l}$ saline was injected intraperitoneally (i.p.) $4 \mathrm{~h}$ before SS-RBC infusion. Generally, an aliquot from each patient sample was infused into three to five mice to allow for meaningful comparisons between treatments (e.g. sevuparin or tinzaparin) and control [sham (saline) treatment], due to the fact that the degree of adhesion is variable among patients. Thus, conclusions about per cent inhibition of adhesion always included a control experiment utilizing the same SS-RBCs as were used for animals receiving an adhesion inhibitor.

The extent of SS-RBC adhesion was determined and expressed as \% vessel occupancy. The sum of vessel lengths along which there were adherent SS-RBCs was divided by the total vessel length examined and is presented as \% SS-RBC occupancy for each vessel. All measurable venules were analysed, and at least 30 vessels for each mouse were measured. The average of these values represented the overall percentage of SS-RBC vessel occupancy in an individual mouse.

All measured vessels were also classified for blood flow status. Vessels were categorized into one of three categories: normal flowing, non-flowing or slow (or intermittent) flowing. Total vessel lengths in each category were summed for each mouse (from 4-5 movies), and the percentage was calculated by the total length of each category divided by the total length of vessels analysed in all three categories.

The degree of adhesion (\% vessel occupancy) and vasoocclusion (\% of vessels with retarded or absent flow) associated with each treatment were first aggregated for multiple observed vessels with the same patient sample and animal. These data were then aggregated among patient samples. The data were compared using GraphPad Prism 4 software using a paired Student's $t$-test, one-way analysis of variance (ANOVA) and Tukey's multiple comparisons test. Specific comparisons between two treatments were performed using unpaired $t$-tests. A $P$-value $<0.05$ was considered to be significant.

\section{Results}

\section{Selectin binding by sevuparin}

Heparinoids have been associated with inhibition of P-selectin-mediated SS-RBC adhesion in SCD (Matsui et al, 2001;
Embury et al, 2004; Kutlar et al, 2012). Therefore, an initial experiment was performed to investigate sevuparin's selectin binding profile in comparison to LMWH and full-length heparin. The sevuparin-selectin interactions were studied by using surface plasmon resonance (SPR) and selectin chimeras in which the selectin ectodomain was combined with an immunoglobulin Fc domain (Scheffler et al, 1995). As sevuparin consists of long carbohydrate chains, it contains several potential binding sites; thus, more than one P-selectin chimera may interact with one sevuparin molecule. Multivalent binding of sevuparin was supported by analysis of the dose-response function of the binding reaction. Assuming a two-site binding model increased the quality of the fit compared with a one-site model. Using a two-site binding model for data analysis, the corresponding dissociation constants $(\mathrm{Kd})$ were calculated as 0.022 and $1.6 \mu \mathrm{mol} / \mathrm{l}$ for heparin, 0.14 and $5.3 \mu \mathrm{mol} / \mathrm{l}$ for sevuparin, and 1.2 and $89 \mu \mathrm{mol} / \mathrm{l}$ for tinzaparin. However, the values from the one-site binding model $(0.22 \mu \mathrm{mol} / \mathrm{l}$ for heparin, $0.73 \mu \mathrm{mol} / \mathrm{l}$ for sevuparin and $3.6 \mu \mathrm{mol} / \mathrm{l}$ for tinzaparin) (Fig 2A) ease the comparison to previously published data. These dissociation constants indicated that the P-selectin binding pattern was better conserved in sevuparin than in the LMWH tinzaparin, for which dissociation constants were considerably higher.

Given that E-selectin-mediated adhesion also has been implicated in SCD VOC, (Turhan et al, 2002; Hidalgo et al, 2009; Chang et al, 2010) we then extended our SPR analyses to chimeras of all three selectins. Kd values were determined using SPR measurements in which E-, P-, and L-selectin chimeras were immobilized on a chip. Sevuparin demonstrated high-affinity binding for both P-selectin (38 nmol/l) and L-selectin $(0.95 \mu \mathrm{mol} / \mathrm{l})$ (Fig $2 \mathrm{~B})$, while the $\mathrm{Kd}$ of sevuparin for E-selectin was $19 \mu \mathrm{mol} / \mathrm{l}$ (Fig 2B), demonstrating that sevuparin bound to E-selectin with low affinity.

\section{Effect of sevuparin on SS-RBC adhesion to HUVECs}

Given the promising results of the selectin binding profile, we then measured the anti-adhesive properties of sevuparin by employing a graduated height flow chamber to directly measure RBC adhesion to cultured HUVECs that had been stimulated with IL13 and histamine to upregulate P-selectin expression. Overall, sevuparin inhibited SS-RBC adhesion to these cells with a clear dose-dependent relationship (Fig 3A). An effect became observable when sevuparin was used at concentrations as low as $10 \mu \mathrm{g} / \mathrm{ml}$, and at 50,100, 200, 400 and $600 \mu \mathrm{g} / \mathrm{ml}$, sevuparin had clear and significant effects $(P=0.006,0.006,0.001,0.037,0.001$, respectively, using a paired $t$-test in which patient samples were compared to tests done in the absence of sevuparin using the same donor samples, see Fig 3A). Inhibition of adhesion was most effective with higher sevuparin doses and in patients' RBCs with higher baseline adhesion. The differences in inhibition 

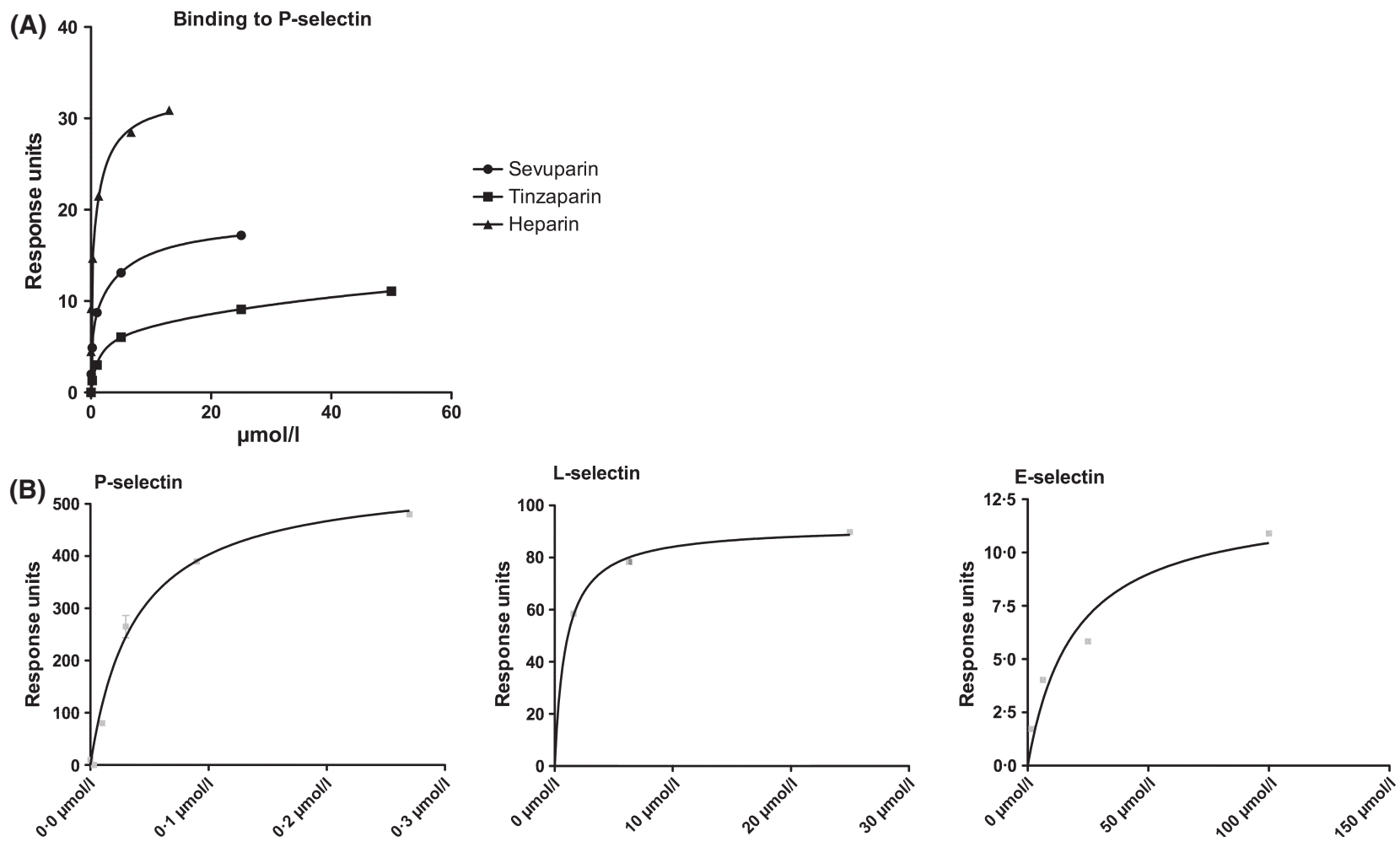

Fig 2. Sevuparin interactions with selectins. (A) Binding of sevuparin, tinzaparin and unfractionated heparin to P-selectin. Binding was recorded by SPR measurements with the heparinoids in solution binding to a P-selectin chimera that was attached to the chip. (B) Representative binding curves of sevuparin binding to E-, P- and L-selectins. P-selectin: The $\mathrm{K}_{\mathrm{d}}$ values were calculated based on sevuparin concentrations of 1.6, 6.3, and $25 \mu \mathrm{mol} / \mathrm{l}$ without $\mathrm{CaCl}_{2}$. L-selectin: The $\mathrm{K}_{\mathrm{d}}$ values were calculated based on sevuparin concentrations of $1 \cdot 6,6 \cdot 3,25$, and $100 \mu \mathrm{mol} / \mathrm{l}$ without $\mathrm{CaCl}_{2}$. E-selectin: The $\mathrm{K}_{\mathrm{d}}$ values were calculated based on sevuparin concentrations of $30-270 \mu \mathrm{mol} / \mathrm{l}$ without $\mathrm{CaCl}_{2}$.

between highly adherent and only moderately adherent SSRBCs were statistically significantly different in the group studied using $100 \mu \mathrm{g} / \mathrm{ml}$ sevuparin $(P=0.02$, data not shown). The capacity of sevuparin to inhibit neutrophil adhesion to HUVECs was also assessed in the flow chamber system; however, higher concentrations of sevuparin were required to achieve significant inhibition of neutrophil adhesion (Figure S1, Data S1). The inhibitory effect of sevuparin on neutrophil adhesion was statistically significant at $400 \mu \mathrm{g} /$ $\mathrm{ml}$, and the effect size continued to increase up to $800 \mu \mathrm{g} / \mathrm{ml}$ in vitro.

\section{P-selectin-mediated adhesion of SS-RBCs}

Heparinoids have been previously shown to block P-selectin (Matsui et al, 2002; Embury et al, 2004). Therefore, to confirm that P-selectin was involved in the adhesion events observed in this study, monoclonal antibody $(\mathrm{mAb})$ clone 9E1 (R\&D Systems) was used to inhibit SS-RBC adhesion to IL13+histamine-stimulated HUVECs. The mAb markedly inhibited SS-RBC adhesion when concentrations of $7.5 \mu \mathrm{g} /$ $\mathrm{ml}$ and $10 \mu \mathrm{g} / \mathrm{ml}$ were used, with $10 \mu \mathrm{g} / \mathrm{ml} \mathrm{9E1} \mathrm{mAb} \mathrm{pro-}$ ducing a similar reduction in adhesion as was observed with $200 \mu \mathrm{g} / \mathrm{ml}$ sevuparin (Fig 3B).
Effect of sevuparin on SS-RBC adhesion and vasoocclusion in vivo

After confirming the anti-adhesive effect of sevuparin in the in vitro assay, we sought to also assess its effect in vivo. Therefore, sevuparin was studied in a mouse model with both an anti-adhesion read-out and the crucial functional read-out of restoring normal blood flow. The results show that sevuparin markedly decreased the degree to which SSRBCs adhered to blood vessel walls in animals that had been pretreated with TNF $\alpha$. (Fig 4A, global analysis of variance $P<0.0001)$. Although the mean \% occupancy observed with a $40 \mathrm{mg} / \mathrm{kg}$ sevuparin dose was only slightly lower than that observed with the $20 \mathrm{mg} / \mathrm{kg}$ dose, the difference between the doses was statistically significant $(P=0.0459)$. When microvascular functionality (blood flow) was investigated, sevuparin clearly demonstrated a dose-dependent capacity to prevent vaso-occlusion, with $20 \mathrm{mg} / \mathrm{kg}$ given subcutaneously demonstrating maximal or near-maximal effect. The read-out is given as the \% of vessels with normal flow, and here a much larger proportion of vessels had normal blood flow after $20 \mathrm{mg} / \mathrm{kg}$ sevuparin than after saline infusion as control $(P=0.0003$, Fig $4 \mathrm{~B})$. For this parameter, $40 \mathrm{mg} / \mathrm{kg}$ sevuparin led to a small and 

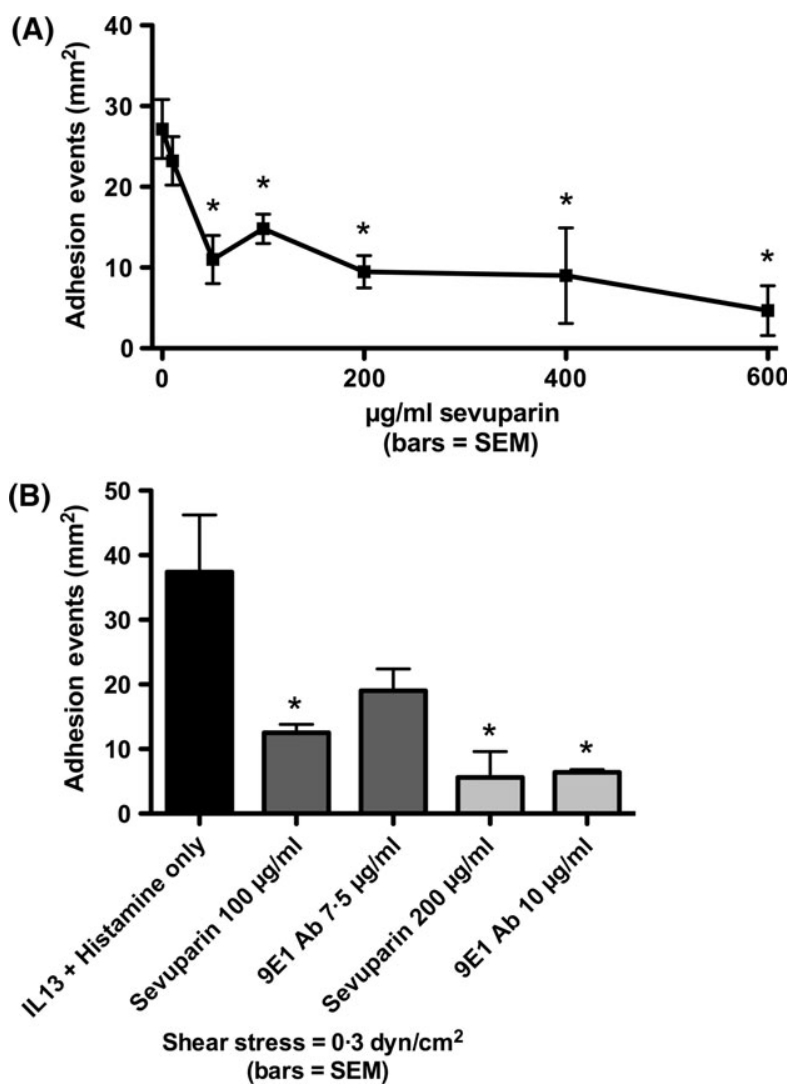

Fig 3. Effect of sevuparin and anti P-selectin monoclonal antibodies on SS-RBC adhesion to HUVECs. (A) Dose response of sevuparin concentration $(\mu \mathrm{g} / \mathrm{ml})$ versus number of adhesive events per $\mathrm{mm}^{2}$ between human SS-RBCs and activated HUVECs, during continuous flow at 0.3 dynes $/ \mathrm{cm}^{2}$. * indicates $P<0.05$ compared to adhesion in the absence of sevuparin. (N: IL13 and histamine only, 20. Sevuparin $10 \mu \mathrm{g} / \mathrm{ml}, 2 ; 50 \mu \mathrm{g} / \mathrm{ml}, 4 ; 100 \mu \mathrm{g} / \mathrm{ml}, 7 ; 200 \mu \mathrm{g}, 6 ; 400 \mu \mathrm{g}, 4 ; 600 \mu \mathrm{g}$, 3.) HUVECs were activated to increase P-selectin expression by IL13 and histamine treatment as described in Materials and methods. (B) Comparison of the effect of sevuparin and anti-P-selectin antibodies on SS-RBC adhesion to activated HUVECs. * indicates $P<0.05$ compared to adhesion in the absence of sevuparin or mAb 9E1. $(\mathrm{N}$ : IL13 and histamine only, 6. Sevuparin $100 \mu \mathrm{g} / \mathrm{ml}, 3 ; 200 \mu \mathrm{g} / \mathrm{ml}, 2$. $9 \mathrm{E} 1 \mathrm{mAb} 7.5 \mu \mathrm{g} / \mathrm{ml}, 4 ; 10 \mu \mathrm{g} / \mathrm{ml}, 2$.)

statistically non-significant improvement of blood flow compared with $20 \mathrm{mg} / \mathrm{kg}$ sevuparin.

\section{Comparison of the anti-adhesive effects of sevuparin and tinzaparin}

Considering the clinically interesting effects on VOC in SCD observed with the LMWH tinzaparin, (Qari et al, 2007) a direct comparison between the anti-adhesive activities of sevuparin and tinzaparin was performed. When the capacity of sevuparin and tinzaparin to inhibit SS-RBC adhesion to endothelial cells in flow chambers in vitro was compared, sevuparin and tinzaparin were equally effective in reducing SS-RBC adhesion at 200 and $400 \mu \mathrm{g} / \mathrm{ml}$ compared with the control (Fig 5A), although due to variability, the differences for control versus sevuparin $400 \mu \mathrm{g} / \mathrm{ml}(P=0.0593)$, did not quite reach statistical significance.

Sevuparin and tinzaparin were also compared in the in vivo model. Each drug reduced vessel occupancy by adherent SS-RBCs to a similar degree at similar $\mathrm{mg} / \mathrm{kg}$ doses (Fig 5B); there were no significant differences between the effects of sevuparin and tinzaparin at any dose. Indeed, the effects exerted by the two compounds are not statistically significantly different (vessel occupancy and blood flow, Fig 5B, C), while the difference between control and drug treatment was significant for all doses of both sevuparin and tinzaparin. The dose-responses were compared with matched controls, and a global statistical data analysis demonstrated that both sevuparin and tinzaparin were able to prevent vaso-occlusion in a dose-dependent manner (Fig 5C).

\section{Target protein profiling}

Taking together the initial selectin binding data and the antiadhesive effects demonstrated both in vitro and in vivo, it could be hypothesized that sevuparin is also blocking additional adhesive interactions through more firm adhesion events, possibly via other adhesion receptors. To address this possibility, a second round of binding interaction studies was performed. FCS was employed to further define the target spectrum of sevuparin in a homogeneous format in solution. The selectins were included in order to to relate these new results to the previously generated data. For direct interaction measurements with target proteins, fluorescein-labelled sevuparin (fluo-sevuparin) was used, which had a diffusional autocorrelation time of $78 \mu$ s, as expected for molecules of this size. A degree of labelling of 0.2 per molecule was calculated by ultraviolet/Vis spectroscopy. At this low level of labelling, a sufficient number of molecules carry a label to allow detection, while the risk of interference with molecular interactions due to multiple labels per molecule should be minimal.

We investigated binding of sevuparin to selected cellular adhesion mediators, including, P-, E- and L-selectins, VWF, TSP and fibronectin (FN). For 1-2 different concentrations of each potential target protein, fluo-sevuparin was titrated over a concentration range of 5-350 $\mathrm{nmol} / \mathrm{l}$, and autocorrelation functions were acquired for each sample. To assess whether interactions changed over time, measurements were conducted both directly after mixing and after a 3-h incubation period (Figures S2 and S3, Data S1). Binding of sevuparin to a target protein slows down diffusion, leading to the appearance of a second component in the autocorrelation function. Fitting of the autocorrelation functions with a twocomponent model, in which one component corresponded to the free and one to the bound sevuparin, yielded the fraction of bound sevuparin. Based on the known concentrations of binding partners in the sample, this was translated into dissociation constants (Table SII, Data S1). E-selectin and FN demonstrated the lowest capacity to bind sevuparin, 

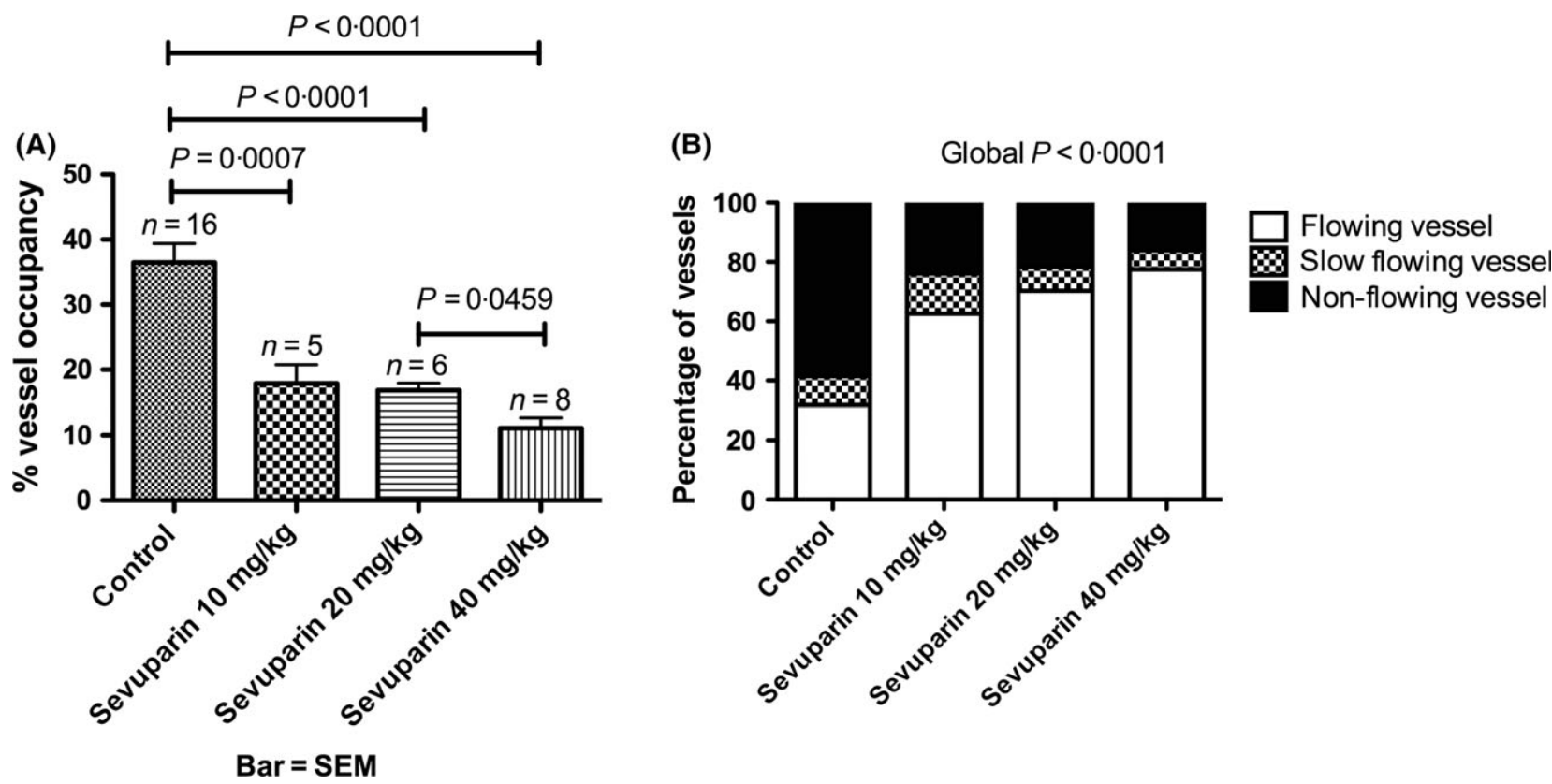

Fig 4. Effect of sevuparin in vivo on SS-RBC adhesion to vessel walls. Microscopic observations of postcapillary venules were conducted through implanted window chambers after infusion of SS-RBCs into the tail veins of nude mice using $20 \times$ magnification. (A) Dose response of sevuparin concentration on vessel wall SS-RBC occupancy reflecting the anti-adhesive properties of sevuparin. The percentage of vessel length with diameters up to $25 \mu \mathrm{m}$ occupied by SS-RBCs was quantified as follows: \% venular length occupied by SS-RBCs $\times$ (length of vessel wall with adherent cells/total length of the vessel segments analysed) $\times 100$. Values are means of $>30$ vessels analysed for each mouse. Error bars show SEM of at least 3 different experiments for each experimental condition. (B) Dose-dependent restoration of vascular function (blood flow) by sevuparin.

although as expected, the fraction of bound ligand increased with sevuparin concentration in both cases. Also as expected, the dissociation constant, as determined from binding equilibria, was independent of the concentration of the labelled sevuparin and the interactor concentration, except for VWF (Figure S2). For VWF, lower dissociation constants were calculated for higher labelled sevuparin concentrations. The reason for this concentration dependence is not clear.

Dissociation constants were also determined by competitive titration of fluorescently labelled sevuparin with unlabelled sevuparin. Two different approaches were used to determine dissociation constants in the presence of unlabelled ligand. The first approach determined dissociation constants for each individual sample as before for the total sevuparin concentration (labelled and unlabelled in the sample, Figure S4, Data S1). The second approach employed the Cheng-Prusoff equation to derive dissociation constants from inhibitory constant (Ki) values for those ligands to which binding of fluorescently labelled ligand could be fully competed (Figures S5, S6 and S7, Data S1).

Overall, there was good accordance for dissociation constants as determined in the absence (first approach, direct titration) and presence of competitive inhibitor and derived from the fraction of bound fluorescent sevuparin (Table I). Also, the dissociation constants for the selectins were in the same range as those determined with the one-site binding model. FN had the highest dissociation constant, followed by E-selectin. L- and P-selectins and VWF displayed low and very similar dissociation constants. Thrombospondin A had the lowest dissociation constant. Similar Kd values for heparinoids have been documented elsewhere (Koenig et al, 1998; Barabino et al, 1999; Wang et al, 2002; Wang \& Geng, 2003; Brittain et al, 2004; Simonis et al, 2007; Gayen Betal \& Setty, 2008).

\section{Discussion}

The results presented here support the hypothesis that sevuparin can improve vascular blood flow in SCD by binding to several key cellular adhesion receptors and plasma components that contribute to vaso-occlusion. Thus, our observations with sevuparin are both of potential clinical importance as well as interesting from the point of view of understanding SCD pathophysiology, as they support the role of antiadhesion therapy in counteracting the causative processes of sickle cell adhesion and vaso-occlusion. Abnormal adhesion between blood cells and the endothelium in SCD has been linked to disease severity (Hebbel et al, 1980b; Setty \& Stuart, 1996; Dworkis et al, 2011). Although the pathophysiology of acute pain episodes is complex and not fully understood, a cascade of cell adhesion events leading to vaso-occlusion and ischemia has been convincingly demonstrated (Manwani \& Frenette, 2013). Therefore, inhibition of abnormal adhesion should restore normal blood flow and thereby result in faster pain relief and reduced tissue injury. Preclinical and early phase clinical studies of various compounds that inhibit 

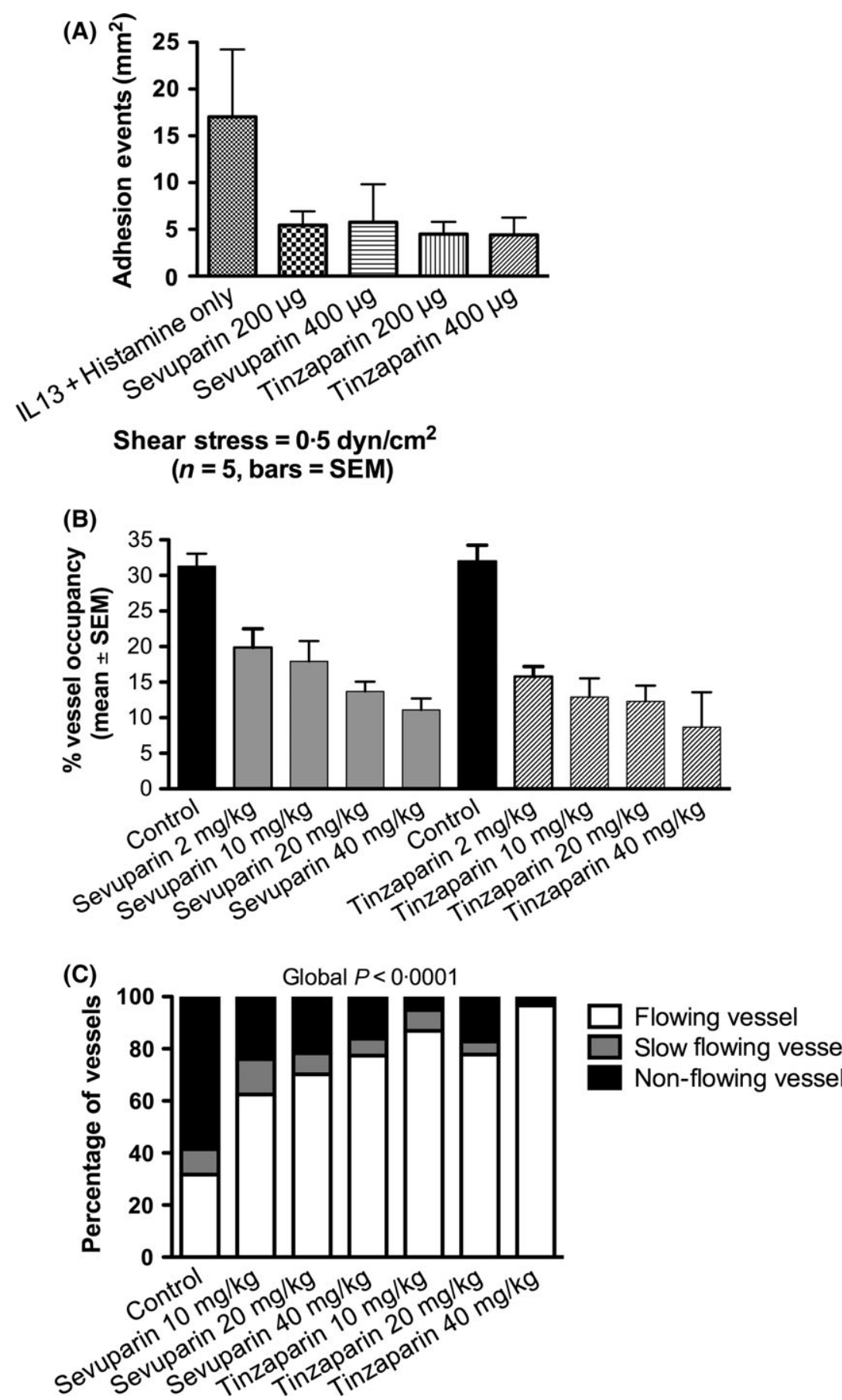

Fig 5. Comparison of the anti-adhesive effects of sevuparin and tinzaparin. (A) Effect of sevuparin compared with tinzaparin on SS-RBC adhesion to HUVECs in vitro. Adhesive events per $\mathrm{mm}^{2}$ were measured as previously described. The relatively large differences in the numbers of adhesive events between controls (IL13 and histamine only) and samples in which sevuparin or tinzaparin were used were not uniformly statistically significant, and the most significant difference was observed for control versus $400 \mu \mathrm{g} / \mathrm{ml}$ sevuparin. Lack of statistically significant differences between control and heparinoids was probably due to variability in adhesivity among patient samples.

(B) Effects of equivalent $\mathrm{mg} / \mathrm{kg}$ sevuparin and tinzaparin doses on vessel wall occupancy by adherent SS-RBCs in vivo. Vessel occupancy is defined as the $\%$ of the vessel wall occupied by adherent, labelled human SS-RBCs. Global statistical analysis of all data by ANOVA demonstrates that both sevuparin and tinzaparin can prevent vaso-occlusion $(P<0.0001)$. There was no statistically significant difference in the effects of the two drugs. (For Panels B and C, $N=4-11$ for each dose of sevuparin and tinzaparin except for tinzaparin $40 \mathrm{mg} / \mathrm{kg}$, for which $N=2$.) (C) The effect of sevuparin in mice in vivo, measured as vessel function. All of the tested sevuparin and tinzaparin doses were effective in improving vessel function (number of flowing vessels) $(P<0 \cdot 0001)$. There were no statistically significant differences when results using equivalent doses of sevuparin and tinzaparin were compared. diverse adhesive interactions further support this hypothesis (Embury et al, 2004; Chang et al, 2008, 2010; Gutsaeva et al, 2011; Manwani et al, 2015; Telen et al, 2015).

Anticoagulation treatment for SCD has been investigated in several studies (Salvaggio et al, 1963; Chaplin et al, 1989; Ahmed et al, 2004; Qari et al, 2007). However, a substantial proportion of patients with SCD are at clinical risk of haemorrhage, often due to intracerebral angiopathy, and especially so-called Moyamoya abnormalities of the central nervous system vasculature. This risk of haemorrhage has contributed to some reluctance to adopt therapeutic anticoagulation either in a prophylactic setting or during vaso-occlusive episodes (Qari et al, 2007). Ruling out the existence of vascular abnormalities that predispose to intracerebral haemorrhage prior to starting treatment would both be cost-prohibitive and delay treatment. Thus, the pharmacological use of anticoagulation treatments remains of undefined risk and benefit in the SCD population.

Heparin also interferes with P-selectin-mediated SS-RBC adhesion to endothelial cells (Matsui et al, 2002). The data 
Table I. Comparison of dissociation constants as determined by FCS using three different analytic approaches.

\begin{tabular}{|c|c|c|c|c|c|c|}
\hline \multirow[b]{2}{*}{ Adhesion protein ${ }^{*}$} & \multicolumn{2}{|c|}{ Kd Direct $(\mu \mathrm{mol} / \mathrm{l})$} & \multicolumn{2}{|c|}{ Kd Titration $(\mu \mathrm{mol} / \mathrm{l})$} & \multirow{2}{*}{$\begin{array}{l}\mathrm{IC}_{50} \\
(\mu \mathrm{mol} / \mathrm{l})\end{array}$} & \multirow{2}{*}{$\begin{array}{l}\text { Ki Cheng } \\
\text { Prusoff }(\mu \mathrm{mol} / \mathrm{l})\end{array}$} \\
\hline & Average & SD & Average & SD & & \\
\hline P-selectin & $-\dagger$ & - & 0.485 & $0 \cdot 38$ & 0.942 & 0.622 \\
\hline E-selectin & $4 \cdot 51$ & 1.52 & $4 \cdot 48$ & - & $-\S$ & $-\S$ \\
\hline L-selectin $5 \mu \mathrm{mol} / \mathrm{l}$ & $0 \cdot 807$ & $0 \cdot 309$ & $0 \cdot 451$ & 0.43 & $-\S$ & $-\S$ \\
\hline Fibronectin & $6 \cdot 51$ & $2 \cdot 44$ & $2 \cdot 25$ & 0.344 & $3 \cdot 15$ & $2 \cdot 97$ \\
\hline von Willebrand factor & $0 \cdot 720 \%$ & $0 \cdot 893+$ & $0 \cdot 479$ & $0 \cdot 126$ & $6 \cdot 45$ & $4 \cdot 55$ \\
\hline Thrombospondin & $0 \cdot 487 \dagger$ & $0 \cdot 238$ & $0 \cdot 419$ & $0 \cdot 180$ & 4.97 & $2 \cdot 97$ \\
\hline
\end{tabular}

$\mathrm{Kd}$ direct refers to averages of dissociation constants derived from binding equilibria with labelled ligand, where bound and free ligand were obtained from two-component fits of the autocorrelation function. Kd titration refers to dissociation constants derived for binding equilibria in the presence of unlabelled ligand. $\mathrm{IC}_{50}$ refers to the concentration of an inhibitor where the response (or binding) is reduced by half. Ki Cheng Prusoff refers to dissociation constants that were determined for those binders where binding of labelled ligand could be fully competed with unlabelled ligand. For determination of dissociation constants via Cheng Prusoff, an average of the Kd titration and the Kd direct was employed. *Adhesion proteins were employed at the following concentrations: P-selectin $3 \mu \mathrm{mol} / \mathrm{l}$, E-selectin $5 \mu \mathrm{mol} / \mathrm{l}$, L-selectin $5 \mu \mathrm{mol} / \mathrm{l}$, fibronectin $10 \mu \mathrm{mol} / \mathrm{l}$, VWF $2 \mu \mathrm{mol} / \mathrm{l}$, Thrombospondin $1.6 \mu \mathrm{mol} / \mathrm{l}$.

$\dagger$ Not determined due to limited amount of material available.

$\$ 1 \mu \mathrm{mol} / \mathrm{l}$ concentration was used for the direct Kd measurements.

$\S$ Not possible to calculate, due to failure to compete out the labelled ligand.

for sevuparin presented here strongly suggest that blocking abnormal cell adhesion represents a mechanism of action deserving of more attention. In in vitro flow chamber experiments, sevuparin was an effective inhibitor of SS-RBC adhesion to endothelial cells. Interestingly, the degree of RBC adhesion to endothelial cells varied among patients, confirming both our previous observations and those of others (Hebbel et al, 1980b; Zennadi et al, 2004). Variability among patients may be linked to both the expression of ligands on the $\mathrm{RBC}$ for various endothelial cell adhesion receptors, including $\mathrm{P}$-selectin and integrin $\alpha \mathrm{v} \beta 3$, and their activation state. Because the RBC ligand for P-selectin is currently unidentified, it was not possible to test this directly. In addition, the activation state of erythroid adhesion receptors probably varies among patients, as previously described (Zen et al, 1999, 2004). Hydroxycarbamide can also affect both adhesion receptor expression as well as adhesion receptor activation, often in opposite directions (Gambero et al, 2007; Odievre et al, 2008; Bartolucci et al, 2010; Chaar et al, 2014). Nonetheless, vaso-occlusion, when it occurs, still occurs through the same mechanisms, with and without hydroxycarbamide. This has recently been seen in the similar effect of another anti-adhesive drug/selectin inhibitor, GMI-1070 (rivipansel), in the presence or absence of hydroxycarbamide (Telen et al, 2015). In vivo, variability of both RBC and leucocyte adhesion may also arise from genetic variability affecting leucocytes and endothelial cells, including indirect effects via inflammatory pathways. This, however, is less likely to be a factor in syngeneic mice.

Our in vivo studies focused on human SS-RBCs to ensure that the drug effects observed were relevant to human disease, because murine SS-RBCs, although reported to also bind P-selectin, (Matsui et al, 2001, 2002) lack several known $\mathrm{RBC}$ adhesion receptors, including $\mathrm{BCAM} / \mathrm{Lu}$ and $\mathrm{CD} 44$,
(Sugimoto et al, 1994; Moulson et al, 2001) which are involved in binding to laminin, FN and leucocytes (Verfaillie et al, 1994; Udani et al, 1998; Zennadi et al, 2008). Nonetheless, at least two major murine endothelial receptors for SS-RBC adhesion are similar enough to the human that reagents that block human SS-RBC adhesion to murine endothelium also block adhesion to human endothelial receptors. Thus, heparins block SS-RBC binding to both human and murine P-selectins (Matsui et al, 2001, 2002) despite the lack in the murine P-selectin of one complementbinding domain (Weller et al, 1992). Likewise, reagents that block adhesion via the $\alpha \mathrm{V} \beta 3$ integrin of endothelial cells do so for both murine and human cells (Kaul \& Hebbel, 2000; Zennadi et al, 2004, 2007).

Although the chronic endotheliopathy and baseline leucocyte activation of SCD is absent, this model system employs TNF-induced activation of both endothelial cells and leucocytes, has repeatedly been proven useful for studying SS-RBC interactions with the endothelium and leucocytes in vivo, and has produced results that have subsequently been replicated in sickle mice and human studies (Zennadi et al, 2007, 2008, 2012; De Castro et al, 2012; Zennadi, 2014). As in similar investigations, two assessments were performed: percentage occupancy as a measure of abnormal adhesion of cells to endothelium, as well as blood flow, which best measures the degree of vaso-occlusion. Unless a vessel is quite narrow, it takes more than one layer of adherent red cells to block blood flow.

Sevuparin clearly demonstrated a dose-dependent capacity to prevent vaso-occlusion, with $20 \mathrm{mg} / \mathrm{kg}$ given subcutaneously demonstrating maximal or near-maximal effect. This effect was clearly related to inhibition of RBC adhesion to the vessel walls, although inhibition of leucocyte adhesion may also have contributed (Figure S1). Furthermore, 


\section{J. Telen et al}

sevuparin has effects similar to tinzaparin at comparable mg/ $\mathrm{kg}$ doses. Given that sevuparin has a confirmed low anticoagulant effect (Lindgren et al, 2015) and because the doseresponse curves for sevuparin and tinzaparin are very similar in our animal model of vaso-occlusion, we conclude that it is primarily the anti-adhesive effect exerted by sevuparin and tinzaparin rather than an anticoagulant effect that is most important for prevention of vaso-occlusion by heparinoids. Notably, sevuparin has no appreciable effect on bleeding time, platelet activation or platelet adhesion.

Binding experiments with isolated potential adhesion receptors suggest that multiple interactions contribute to the anti-adhesive effect of sevuparin. Employing a combination of two orthogonal methods to investigate binding interactions, SPR and FCS, sevuparin demonstrated significant binding to P-selectin, L-selectin, VWF, TSP and FN, but only weak binding to E-selectin (Table S2). Compared with Pselectin and L-selectin, there was only very weak binding to E-selectin (Fig 2 and Figure S2). Sevuparin's low or limited affinity to E-selectin is in line with published data on heparin (Koenig et al, 1998). Furthermore, SPR data support the notion that sevuparin engages in multivalent binding, i.e., one sevuparin chain interacting with several P-selectin molecules at the same time. In addition, the difference observed in heparinoid-binding affinity to selectins when using $\mu \mathrm{mol} / \mathrm{l}$ or $\mathrm{nmol} / \mathrm{l}$ levels of the ligand may reflect these multivalent interactions; thus, when incubating at only nmol/l concentrations, only the high-affinity site/interactions are detected, while at $\mu \mathrm{mol} / \mathrm{l}$ concentrations, the Kd values reflect a combination of two or more interaction sites.

It is well-known that heparin has many pharmacological properties other than its effect on anticoagulation (Mulloy et al, 2016). However, less is known about the mechanisms of these other activities. Here, we have used two different methods to investigate the binding of sevuparin to previously identified heparin-binding proteins known to contribute to the abnormal adhesion seen in SCD. FN, VWF and TSP are recognized as complex to study from a biochemical binding perspective, as they can interact in multiple ways (multivalent) and also form oligomers (Barabino et al, 1999; Tan \& Ginsburg, 2008). There are many similarities between heparin's polypharmacological anti-inflammatory mechanism and sevuparin's mechanism of action as elucidated here. It is reasonable to speculate that sevuparin acts at several steps in the cascade leading to vaso-occlusion, much like the complex anti-inflammatory effects observed for heparin. For example, by binding $\mathrm{P}$ - and L-selectin, sevuparin probably blocks the initial rolling of blood cells on the endothelium. Then, firm adhesion may be abrogated by sevuparin binding to the bridging proteins VWF, FN and TSP, thus hindering the interactions between integrins on the activated endothelium and the blood cells.

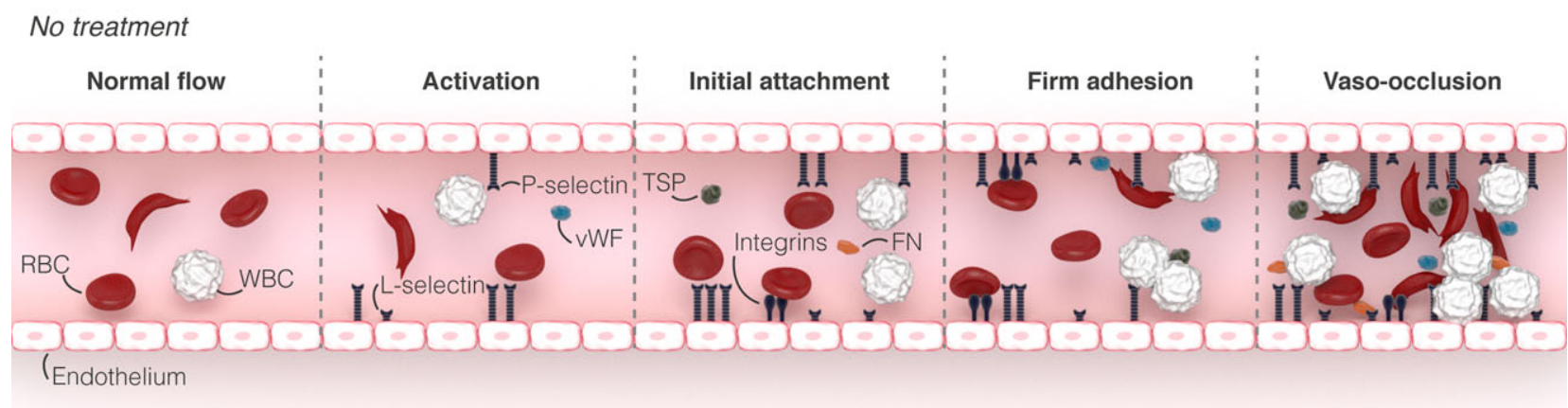

Sevuparin treatment

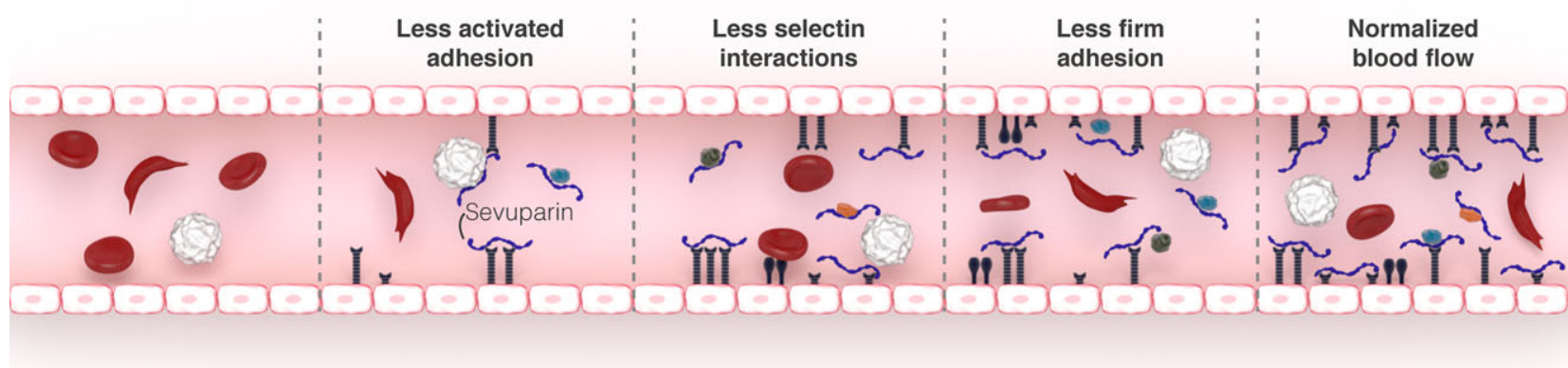

Fig 6. Potential multimodal mechanism of sevuparin action. This figure demonstrates the potential interactions between SS-RBCs and the blood vessel wall endothelium. See figure for explanation of respective symbols. FN, fibronectin; RBC, red blood cell; TSP, thrombospondin; VWF, von Willebrand factor; WBC, white blood cell. 
To further understand which of the interactions would be likely to be relevant in the clinical setting, a pharmacokinetic bridge study was performed in mice (Table SIII, Data S1). From this, the effective dose (which is $20 \mathrm{mg} / \mathrm{kg}$ in the in vivo model) was translated into an effective target plasma concentration of $20 \mu \mathrm{g} / \mathrm{ml}$ (corresponding to about $2.5 \mu \mathrm{mol} / \mathrm{l})$. At this concentration, sevuparin would bind to the adhesion proteins P-selectin, L-selectin, VWF, TSP and (potentially) FN, while the interaction with E-selectin would be limited (illustrated in Fig 6). The capability of sevuparin to interact with several potential targets of SS-RBC adhesion could be of critical importance in VOC, as blockade of multiple interactions is likely to be beneficial in interrupting abnormal adhesion.

The capacity of sevuparin to prevent or reverse VOC and the resulting pain in clinical use remains to be confirmed. Clinical phase II studies have now been initiated (https://clinicaltrials.gov/ct2/show/NCT02515838; https:// www.clinicaltrialsregister.eu/ctr-search/trial/2014-004416-11/ $\mathrm{NL}$ ). Based on the proposed mechanism of action of sevuparin and the activity we have observed, we expect sevuparin to be an effective new treatment for SCD patients who are experiencing vaso-occlusive events.

\section{Acknowledgements}

We thank all of the individuals who participated in the studies performed. In particular we would like to mention PerOlov Eriksson and Erik Holmer for their heparin and sevuparin knowledge; Dagmar Pikas who did the original SPR on the heparins on P-selectin; the team at VELA-labs in Austria for the work on selectin and sevuparin interactions; Christina Herder, Anneli Hällgren and Mats Wahlgren for fruitful discussion. We especially recognize Andrew Fontanella's assistance in in vivo image analysis. This work was supported by Dilaforette, SA, Sweden via research contracts with Duke University (Dr. Telen) and Radboud University Medical Centre (Dr. Brock).

\section{Author contributions}

M.J.T. designed and supervised the research study, analysed and interpreted all the data, and wrote the manuscript; M.B. performed all in vitro adhesion experiments and analysed in vitro data; S.S. performed all in vivo experiments and analysed in vivo data; P.H. B-G. performed and analysed the FCS experiments; R.Z. helped design and analyse in vivo experiments; A.L. helped design and analyse in vitro experiments; R.B. planned the FCS experiments, analysed the data, and helped write and edit the manuscript; M.L. helped analyse the data and write and edit the manuscript.

\section{Conflict of interest}

M.J.T. and R.B. received support for travel to study-related meetings, and their institutions, including other authors at their institutions, received research support through contract research agreements. A.L. and M.L. are employees of Dilaforette SA. M.J. T. reports other research funding (NIH, Doris Duke Charitable Foundation, Pfizer, Inc.).

\section{Supporting Information}

Additional Supporting Information may be found in the online version of this article:

Data S1: Supplemental Material.

Table SI. The specific anticoagulant activity of sevuparin measured in vitro with standard European Pharmacopoeia methods.

Table SII. Dissociation constants $\left(\mathrm{K}_{\mathrm{D}}\right)$ by direct binding.

Table SIII. Pharmacokinetic parameters of sevuparin.

Fig S1. Effect of sevuparin on adhesion of sickle and normal polymorphonuclear leukocytes (PMNs).

Fig S2. Example graphs of direct binding of fluo-sevuparin as summarised in Table S1.

Fig S3. Examples of control parameters and time dependence of interactions.

Fig S4. Example for the time dependence of binding equilibria.

Fig S5. Competitive titrations of fluo-sevuparin complexes with unlabeled sevuparin.

Fig S6. Competitions for selectins.

Fig S7. Concentration dependence of dissociation constants as determined from competition experiments.

\section{References}

Ahmed, S., Siddiqui, A.K., Iqbal, U., Sison, C.P., Shahid, R.K., Sheth, M., Patel, D.V. \& Russo, L.A. (2004) Effect of low-dose warfarin on Ddimer levels during sickle cell vaso-occlusive crisis: a brief report. European Journal of Haematology, 72, 213-216.

Ataga, K.I., Brittain, J.E., Desai, P., May, R., Jones, S., Delaney, J., Strayhorn, D., Hinderliter, A. \& Key, N.S. (2012) Association of coagulation activation with clinical complications in sickle cell disease. PLOS ONE, 7, e29786.

Ballas, S.K. \& Darbari, D.S. (2013) Neuropathy, neuropathic pain, and sickle cell disease. American Journal of Hematology, 88, 927-929.

Barabino, G.A., Liu, X.D., Ewenstein, B.M. \& Kaul, D.K. (1999) Anionic polysaccharides inhibit adhesion of sickle erythrocytes to the vascular endothelium and result in improved hemodynamic behavior. Blood, 93, 1422-1429.

Bartolucci, P., Chaar, V., Picot, J., Bachir, D., Habibi, A., Fauroux, C., Galacteros, F., Colin,
Y., Le Van Kim, C. \& El Nemer, W. (2010) Decreased sickle red blood cell adhesion to laminin by hydroxyurea is associated with inhibition of Lu/BCAM protein phosphorylation. Blood, 116, 2152-2159.

Brittain, H.A., Eckman, J.R., Swerlick, R.A., Howard, R.J. \& Wick, T.M. (1993) Thrombospondin from activated platelets promotes sickle erythrocyte adherence to human microvascular endothelium under physiologic flow: a potential role for platelet activation in sickle cell vaso-occlusion. Blood, 81, 2137-2143. 


\section{J. Telen et al}

Brittain, J.E., Mlinar, K.J., Anderson, C.S., Orringer, E.P. \& Parise, L.V. (2001a) Activation of sickle red blood cell adhesion via integrin-associated protein/CD47-induced signal transduction. The Journal of Clinical Investigation, 107, 1555-1562.

Brittain, J.E., Mlinar, K.J., Anderson, C.S., Orringer, E.P. \& Parise, L.V. (2001b) Integrin-associated protein is an adhesion receptor on sickle red blood cells for immobilized thrombospondin. Blood, 97, 2159-2164.

Brittain, J.E., Han, J., Ataga, K.I., Orringer, E.P. \& Parise, L.V. (2004) Mechanism of CD47-induced alpha4betal integrin activation and adhesion in sickle reticulocytes. Journal of Biological Chemistry, 279, 42393-42402.

Brown, M.D., Wick, T.M. \& Eckman, J.R. (2001) Activation of vascular endothelial cell adhesion molecule expression by sickle blood cells. Pediatric Pathology \& Molecular Medicine, 20, 47-72.

Burnette, A.D., Nimjee, S.M., Batchvarova, M., Zennadi, R., Telen, M.J., Nishimura, J. \& Sullenger, B.A. (2011) RNA aptamer therapy for vaso-occlusion in sickle cell disease. Nucleic Acid Therapeutics, 21, 275-283.

Chaar, V., Laurance, S., Lapoumeroulie, C., Cochet, S., De Grandis, M., Colin, Y., Elion, J., Le Van Kim, C. \& El Nemer, W. (2014) Hydroxycarbamide decreases sickle reticulocyte adhesion to resting endothelium by inhibiting endothelial lutheran/basal cell adhesion molecule (Lu/ BCAM) through phosphodiesterase $4 \mathrm{~A}$ activation. Journal of Biological Chemistry, 289, 1151211521.

Chang, J., Shi, P.A., Chiang, E.Y. \& Frenette, P.S. (2008) Intravenous immunoglobulins reverse acute vaso-occlusive crises in sickle cell mice through rapid inhibition of neutrophil adhesion. Blood, 111, 915-923.

Chang, J., Patton, J.T., Sarkar, A., Ernst, B., Magnani, J.L. \& Frenette, P.S. (2010) GMI-1070, a novel pan-selectin antagonist, reverses acute vascular occlusions in sickle cell mice. Blood, 116, 1779-1786.

Chaplin, H. Jr, Monroe, M.C., Malecek, A.C., Morgan, L.K., Michael, J. \& Murphy, W.A. (1989) Preliminary trial of minidose heparin prophylaxis for painful sickle cell crises. East African Medical Journal, 66, 574-584.

Chen, J., Hobbs, W.E., Le, J., Lenting, P.J., de Groot, P.G. \& Lopez, J.A. (2011) The rate of hemolysis in sickle cell disease correlates with the quantity of active von Willebrand factor in the plasma. Blood, 117, 3680-3683.

De Castro, L.M., Zennadi, R., Jonassaint, J.C., Batchvarova, M. \& Telen, M.J. (2012) Effect of propranolol as antiadhesive therapy in sickle cell disease. Clinical and Translational Science, 5, 437444.

Dworkis, D.A., Klings, E.S., Solovieff, N., Li, G., Milton, J.N., Hartley, S.W., Melista, E., Parente, J., Sebastiani, P., Steinberg, M.H. \& Baldwin, C.T. (2011) Severe sickle cell anemia is associated with increased plasma levels of TNF-R1 and VCAM-1. American Journal of Hematology, 86, 220-223.
Ebnet, K. \& Vestweber, D. (1999) Molecular mechanisms that control leukocyte extravasation: the selectins and the chemokines. Histochemistry and Cell Biology, 112, 1-23.

Embury, S.H., Matsui, N.M., Ramanujam, S., Mayadas, T.N., Noguchi, C.T., Diwan, B.A., Mohandas, N. \& Cheung, A.T.W. (2004) The contribution of endothelial cell P-selectin to the microvascular flow of mouse sickle erythrocytes in vivo. Blood, 104, 3378-3385.

Faulcon, L.M., Fu, Z., Dulloor, P., Barron-Casella, E., Savage, W., Jennings, J.M., Van Eyk, J.E., Debaun, M., Casella, J.F. \& Everett, A. (2013) Thrombospondin-1 and L-selectin are associated with silent cerebral infarct in children with sickle cell anaemia. British Journal of Haematology, 162, 421-424.

Finnegan, E.M., Barabino, G.A., Liu, X.D., Chang, H.Y., Jonczyk, A. \& Kaul, D.K. (2007a) Smallmolecule cyclic alpha $\mathrm{V}$ beta 3 antagonists inhibit sickle red cell adhesion to vascular endothelium and vasoocclusion. American Journal of Physiology. Heart and Circulatory Physiology, 293, H1038-H1045.

Finnegan, E.M., Turhan, A., Golan, D.E. \& Barabino, G.A. (2007b) Adherent leukocytes capture sickle erythrocytes in an in vitro flow model of vaso-occlusion. American Journal of Hematology, 82, 266-275.

Frenette, P.S. (2002) Sickle cell vaso-occlusion: multistep and multicellular paradigm. Current Opinion in Hematology, 9, 101-106.

Gambero, S., Canalli, A.A., Traina, F., Albuquerque, D.M., Saad, S.T., Costa, F.F. \& Conran, N. (2007) Therapy with hydroxyurea is associated with reduced adhesion molecule gene and protein expression in sickle red cells with a concomitant reduction in adhesive properties. European Journal of Haematology, 78, 144-151.

Gayen Betal, S. \& Setty, B.N. (2008) Phosphatidylserine-positive erythrocytes bind to immobilized and soluble thrombospondin-1 via its heparin-binding domain. Translational Research, 152, 165-177.

Gupta, K., Gupta, P., Solovey, A. \& Hebbel, R.P. (1999) Mechanism of interaction of thrombospondin with human endothelium and inhibition of sickle erythrocyte adhesion to human endothelial cells by heparin. Biochimica et Biophysica Acta, 1453, 63-73.

Gutsaeva, D.R., Parkerson, J.B., Yerigenahally, S.D., Kurz, J.C., Schaub, R.G., Ikuta, T. \& Head, C.A. (2011) Inhibition of cell adhesion by antiP-selectin aptamer: a new potential therapeutic agent for sickle cell disease. Blood, 117, 727-735.

Hebbel, R.P., Yamada, O., Moldow, C.F., Jacob, H.S., White, J.G. \& Eaton, J.W. (1980a) Abnormal adherence of sickle erythrocytes to cultured vascular endothelium: possible mechanism for microvascular occlusion in sickle cell disease. The Journal of Clinical Investigation, 65, 154 160.

Hebbel, R.P., Boogaerts, M.A., Koresawa, S., Jacob, H.S., Eaton, J.W. \& Steinberg, M.H. (1980b) Erythrocyte adherence to endothelium as a determinant of vasocclusive severity in sickle cell disease. Transactions of the Association of American Physicians, 93, 94-99.

Hidalgo, A., Chang, J., Jang, J.E., Peired, A.J., Chiang, E.Y. \& Frenette, P.S. (2009) Heterotypic interactions enabled by polarized neutrophil microdomains mediate thromboinflammatory injury. Nature Medicine, 15, 384-391.

Kaul, D.K. \& Hebbel, R.P. (2000) Hypoxia/reoxygenation causes inflammatory response in transgenic sickle mice but not in normal mice. The Journal of Clinical Investigation, 106, 411-420.

Kaul, D.K., Tsai, H.M., Liu, X.D., Nakada, M.T., Nagel, R.L. \& Coller, B.S. (2000) Monoclonal antibodies to alphaVbeta3 (7E3 and LM609) inhibit sickle red blood cell-endothelium interactions induced by platelet-activating factor. Blood, 95, 368-374.

Kaul, D.K., Liu, X.D., Zhang, X., Mankelow, T., Parsons, S., Spring, F., An, X., Mohandas, N., Anstee, D. \& Chasis, J.A. (2006) Peptides based on alphaV-binding domains of erythrocyte ICAM-4 inhibit sickle red cell-endothelial interactions and vaso-occlusion in the microcirculation. American Journal of Physiology. Cell Physiology, 291, C922-C930.

Kinney, T.R., Sleeper, L.A., Wang, W.C., Zimmerman, R.A., Pegelow, C.H., Ohene-Frempong, K., Wethers, D.L., Bello, J.A., Vichinsky, E.P., Moser, F.G., Gallagher, D.M., DeBaun, M.R., Platt, O.S. \& Miller, S.T. (1999) Silent cerebral infarcts in sickle cell anemia: a risk factor analysis. The Cooperative Study of Sickle Cell Disease. Pediatrics, 103, 640-645.

Koenig, A., Norgard-Sumnicht, K., Linhardt, R. \& Varki, A. (1998) Differential interactions of heparin and heparan sulfate glycosaminoglycans with the selectins. Implications for the use of unfractionated and low molecular weight heparins as therapeutic agents. The Journal of Clinical Investigation, 101, 877-889.

Koppel, D.E. (1974) Statistical accuracy in fluorescence correlation spectroscopy. Physical Review, 10, 1938-1945.

Krishnan, S., Siegel, J., Pullen, G. Jr, Hevelow, M., Dampier, C. \& Stuart, M. (2008) Increased von Willebrand factor antigen and high molecular weight multimers in sickle cell disease associated with nocturnal hypoxemia. Thrombosis Research, 122, 455-458.

Kutlar, A., Ataga, K.I., McMahon, L., Howard, J., Galacteros, F., Hagar, W., Vichinsky, E., Cheung, A.T., Matsui, N. \& Embury, S.H. (2012) A potent oral P-selectin blocking agent improves microcirculatory blood flow and a marker of endothelial cell injury in patients with sickle cell disease. American Journal of Hematology, 87, 536-539.

Langer, H.F. \& Chavakis, T. (2009) Leukocyteendothelial interactions in inflammation. Journal of Cellular and Molecular Medicine, 13, 12111220.

Lever, R. \& Page, C.P. (2002) Novel drug development opportunities for heparin. Nature Reviews. Drug Discovery, 1, 140-148. 
Lindgren, M., Meijers, J.C.M., Biemond, B.J., Ramstrom, S., Lindahl, T.L., Eriksson, P.-O., Leitgeb, A.M., Wahlgren, M., Hogwood, J., Gray, E. \& Holmer, E. (2015) Sevuparin; effects on hemostasis of a novel polysaccharide drug derived from heparin. Journal of Thrombosis and Haemostasis, 13, 369.

Mader, O., Reiner, K., Egelhaaf, H.-J., Fischer, R. \& Brock, R. (2004) Structure property analysis of pentamethine indocyanine dyes: identification of a new dye for life science applications. Bioconjugate Chemistry, 15, 70-78.

Manwani, D. \& Frenette, P.S. (2013) Vaso-occlusion in sickle cell disease: pathophysiology and novel targeted therapies. Blood, 122, 3892-3898.

Manwani, D., Chen, G., Carullo, V., Serban, S., Olowokure, O., Jang, J., Huggins, M., Cohen, H.W., Billett, H., Atweh, G.F., Frenette, P.S. \& Shi, P.A. (2015) Single-dose intravenous gammaglobulin can stabilize neutrophil Mac-1 activation in sickle cell pain crisis. American Journal of Hematology, 90, 381-385.

Matsui, N.M., Borsig, L., Rosen, S.D., Yaghmai, M., Varki, A. \& Embury, S.H. (2001) P-selectin mediates the adhesion of sickle erythrocytes to the endothelium. Blood, 98, 1955-1962.

Matsui, N.M., Varki, A. \& Embury, S.H. (2002) Heparin inhibits the flow adhesion of sickle red blood cells to P-selectin. Blood, 100, 3790-3796.

de Montalembert, M. (2008) Management of sickle cell disease. BMJ, 337, a1397.

Moulson, C.L., Li, C. \& Miner, J.H. (2001) Localization of Lutheran, a novel laminin receptor, in normal, knockout, and transgenic mice suggests an interaction with laminin alpha5 in vivo. Developmental Dynamics, 222, 101-114.

Mulloy, B., Hogwood, J., Gray, E., Lever, R. \& Page, C.P. (2016) Pharmacology of Heparin and Related Drugs. Pharmacological Reviews, 68, 76141.

Novelli, E.M., Kato, G.J., Ragni, M.V., Zhang, Y., Hildesheim, M.E., Nouraie, M., Barge, S., Meyer, M.P., Hassett, A.C., Gordeuk, V.R., Gladwin, M.T. \& Isenberg, J.S. (2012) Plasma thrombospondin-1 is increased during acute sickle cell vaso-occlusive events and associated with acute chest syndrome, hydroxyurea therapy, and lower hemolytic rates. American Journal of Hematology, 87, 326-330.

Odievre, M.H., Bony, V., Benkerrou, M., Lapoumeroulie, C., Alberti, C., Ducrocq, R., Jacqz-Aigrain, E., Elion, J. \& Cartron, J.P. (2008) Modulation of erythroid adhesion receptor expression by hydroxyurea in children with sickle cell disease. Haematologica, 93, 502-510.

Parent, C. \& Eichacker, P.Q. (1999) Neutrophil and endothelial cell interactions in sepsis. The role of adhesion molecules. Infectious Disease Clinics of North America, 13, 427-447, x.

Pathare, A., Kindi, S.A., Daar, S. \& Dennison, D. (2003) Cytokines in sickle cell disease. Hematology, 8, 329-337.

Polanowska-Grabowska, R., Wallace, K., Field, J.J., Chen, L., Marshall, M.A., Figler, R., Gear, A.R. \& Linden, J. (2010) P-selectin-mediated platelet- neutrophil aggregate formation activates neutrophils in mouse and human sickle cell disease. Arteriosclerosis, Thrombosis, and Vascular Biology, 30, 2392-2399.

Qari, M.H., Aljaouni, S.K., Alardawi, M.S., Fatani, H., Alsayes, F.M., Zografos, P., Alsaigh, M., Alalfi, A., Alamin, M., Gadi, A. \& Mousa, S.A. (2007) Reduction of painful vaso-occlusive crisis of sickle cell anaemia by tinzaparin in a doubleblind randomized trial. Thrombosis and Haemostasis, 98, 392-396.

Salvaggio, J.E., Arnold, C.A. \& Banov, C.H. (1963) Long-term anti-coagulation in sickle-cell disease. A clinical study. New England Journal of Medicine, 269, 182-186.

Scheffler, K., Ernst, B., Katopodis, A., Magnani, J.L., Wang, W.T., Weisemann, R. \& Peters, T. (1995) Determination of the bioactive conformation of the carbohydrate ligand in the Eselectin/sialyl LewisX complex. Angewandte Chemie (International ed. in English), 34, 18411844.

Setty, B.N. \& Stuart, M.J. (1996) Vascular cell adhesion molecule-1 is involved in mediating hypoxia-induced sickle red blood cell adherence to endothelium: potential role in sickle cell disease. Blood, 88, 2311-2320.

Shah, N., Willen, S., Telen, M.J. \& Ortel, T.L. (2013) Prophylactic dose low molecular weight heparin (dalteparin) for treatment of vasoocclusive pain crisis in patients with sickle cell disease. Blood, 122, 2241.

Simonis, D., Christ, K., Alban, S. \& Bendas, G. (2007) Affinity and kinetics of different heparins binding to $\mathrm{P}$ - and L-selectin. Seminars in Thrombosis and Hemostasis, 33, 534-539.

Sparkenbaugh, E. \& Pawlinski, R. (2013) Interplay between coagulation and vascular inflammation in sickle cell disease. British Journal of Haematology, 162, 3-14.

Steinberg, M.H. (2011) In the clinic. Sickle cell disease. Annals of Internal Medicine, 155, ITC31-15; quiz ITC316.

Sugimoto, K., Tsurumaki, Y., Hoshi, H., Kadowaki, S., LeBousse-Kerdiles, M.C., SmadjaJoffe, F. \& Mori, K.J. (1994) Effects of antiCD44 monoclonal antibody on adhesion of erythroid leukemic cells (ELM-I-1) to hematopoietic supportive cells (MS-5): CD44, but not hyaluronate-mediated, cell-cell adhesion. Experimental Hematology, 22, 488-494.

Tan, F.L. \& Ginsburg, D. (2008) What a polyclonal antibody sees in von Willebrand factor. Thrombosis Research, 121, 519-526.

Telen, M.J., Wun, T., McCavit, T.L., De Castro, L.M., Krishnamurti, L., Lanzkron, S., Hsu, L.L., Smith, W.R., Rhee, S., Magnani, J.L. \& Thackray, H. (2015) Randomized phase 2 study of GMI-1070 in SCD: reduction in time to resolution of vaso-occlusive events and decreased opioid use. Blood, 125, 2656-2664.

Trinh-Trang-Tan, M.M., Vilela-Lamego, C., Picot, J., Wautier, M.P. \& Cartron, J.P. (2010) Intercellular adhesion molecule-4 and CD36 are implicated in the abnormal adhesiveness of sickle cell SAD mouse erythrocytes to endothelium. Haematologica, 95, 730-737.

Turhan, A., Weiss, L.A., Mohandas, N., Coller, B.S. \& Frenette, P.S. (2002) Primary role for adherent leukocytes in sickle cell vascular occlusion: a new paradigm. Proceedings of the National Academy of Sciences of the United States of America, 99, 3047-3051.

Udani, M., Zen, Q., Cottman, M., Leonard, N., Jefferson, S., Daymont, C., Truskey, G. \& Telen, M.J. (1998) Basal cell adhesion molecule/ lutheran protein. The receptor critical for sickle cell adhesion to laminin. The Journal of Clinical Investigation, 101, 2550-2558.

Verfaillie, C.M., Benis, A., Iida, J., McGlave, P.B. \& McCarthy, J.B. (1994) Adhesion of committed human hematopoietic progenitors to synthetic peptides from the C-terminal heparin-binding domain of fibronectin: cooperation between the integrin alpha 4 beta 1 and the CD44 adhesion receptor. Blood, 84, 1802-1811.

Wang, J.G. \& Geng, J.G. (2003) Affinity and kinetics of P-selectin binding to heparin. Thrombosis and Haemostasis, 90, 309-316.

Wang, L., Brown, J.R., Varki, A. \& Esko, J.D. (2002) Heparin's anti-inflammatory effects require glucosamine 6-O-sulfation and are mediated by blockade of L- and P-selectins. The Journal of Clinical Investigation, 110, 127-136.

Weatherall, D.J. (2010) The inherited diseases of hemoglobin are an emerging global health burden. Blood, 115, 4331-4336.

Weller, A., Isenmann, S. \& Vestweber, D. (1992) Cloning of the mouse endothelial selectins. Expression of both E- and P-selectin is inducible by tumor necrosis factor alpha. Journal of Biological Chemistry, 267, 15176-15183.

Zen, Q., Cottman, M., Truskey, G., Fraser, R. \& Telen, M.J. (1999) Critical factors in basal cell adhesion molecule/lutheran-mediated adhesion to laminin. Journal of Biological Chemistry, 274, 728-734.

Zen, Q., Batchvarova, M., Twyman, C.A., Eyler, C.E., Qiu, H., De Castro, L.M. \& Telen, M.J. (2004) B-CAM/LU expression and the role of BCAM/LU activation in binding of low- and high-density red cells to laminin in sickle cell disease. American Journal of Hematology, 75, 63 72 .

Zennadi, R. (2014) MEK inhibitors, novel antiadhesive molecules, reduce sickle red blood cell adhesion in vitro and in vivo, and vasoocclusion in vivo. PLoS ONE, 9, e110306.

Zennadi, R., Hines, P.C., De Castro, L.M., Cartron, J.P., Parise, L.V. \& Telen, M.J. (2004) Epinephrine acts through erythroid signaling pathways to activate sickle cell adhesion to endothelium via LW-alphavbeta3 interactions. Blood, 104, 3774 3781.

Zennadi, R., Moeller, B.J., Whalen, E.J., Batchvarova, M., Xu, K., Shan, S., Delahunty, M., Dewhirst, M.W. \& Telen, M.J. (2007) Epinephrine-induced activation of LW-mediated sickle cell adhesion and vaso-occlusion in vivo. Blood, $110,2708-2717$ 


\section{J. Telen et al}

Zennadi, R., Chien, A., Xu, K., Batchvarova, M. \& Telen, M.J. (2008) Sickle red cells induce adhesion of lymphocytes and monocytes to endothelium. Blood, 112, 3474-3483.

Zennadi, R., Whalen, E.J., Soderblom, E.J., Alexander, S.C., Thompson, J.W., Dubois, L.G., Moseley, M.A. \& Telen, M.J. (2012) Erythrocyte plasma membrane-bound ERK1/2 activation promotes ICAM-4-mediated sickle red cell adhesion to endothelium. Blood, 119, 1217-1227.

Zhao, Y., Schwartz, E.A., Palmer, G.M. \& Zennadi, R. (2016) MEK1/2 inhibitors reverse acute vascular occlusion in mouse models of sickle cell disease. FASEB Journal, 30, 1171-1186.
Zhou, Z., Han, H., Cruz, M.A., Lopez, J.A., Dong, J.F. \& Guchhait, P. (2009) Haemoglobin blocks von Willebrand factor proteolysis by ADAMTS13: a mechanism associated with sickle cell disease. Thrombosis and Haemostasis, 101, 10701077. 